\title{
WEB Intrasaccular Flow Disruptor-Prospective, Multicenter Experience in 83 Patients with 85 Aneurysms
}

\author{
C. Papagiannaki, L. Spelle, A.-C. Januel, A. Benaissa, J.-Y. Gauvrit, V. Costalat, H. Desal, F. Turjman, S. Velasco, X. Barreau, \\ P. Courtheoux, C. Cognard, D. Herbreteau, J. Moret, and L. Pierot
}

\begin{abstract}
BACKGROUND AND PURPOSE: The safety and efficacy of WEB flow disruption have been analyzed in small, retrospective series. The object of this study was to evaluate the safety and efficacy of WEB flow disruption in a large, multicenter, prospectively collected population.
\end{abstract}

\begin{abstract}
MATERIALS AND METHODS: Data from all patients treated with the WEB-DL device between June 2011 and October 2013 in 11 French neurointerventional centers were prospectively collected and retrospectively analyzed. Complications occurring during and after treatment were analyzed as well as morbidity and mortality at 1 month. Aneurysm occlusion status at the last follow-up was analyzed.

RESULTS: Eighty-three patients with 85 aneurysms were included in this series. Technical success was achieved in 77 patients with 79 aneurysms (92.9\%). Periprocedural complications were observed in 9 patients (10.8\%), leading to permanent neurologic deficits in 3 (3.9\%). Morbidity and mortality at 1 month were $1.3 \%$ and $0.0 \%$, respectively. Angiographic follow-up was performed for $65 / 79$ aneurysms (82.3\%) 3-24 months after treatment (mean, 5.3 months). Complete aneurysm occlusion was observed in 37/65 aneurysms (56.9\%); neck remnant, in 23/65 (35.4\%); and aneurysm remnant, in 5/65 (7.7\%).
\end{abstract}

CONCLUSIONS: In this large prospective series of patients, WEB flow disruption was a safe and efficient technique.

ABBREVIATIONS: AcomA = anterior communicating artery; ATENA = Analysis of Treatment by Endovascular Approach of Nonruptured Aneurysms; CLARITY= Clinical and Anatomic Results in the Treatment of Ruptured Intracranial Aneurysms; DL = Dual Layer; WEB = Woven Endoluminal Bridge

$E^{\prime}$ ndovascular treatment is now the first therapeutic option for ruptured aneurysms and is important in the treatment of unruptured aneurysms. ${ }^{1-3}$ Aneurysms with a complex anatomy (fusiform, wideneck, large, or giant) are in some cases untreatable or difficult to treat with standard coiling. For these cases, endovascular techniques such as balloon-assisted coiling, stent-assisted coiling, or flow diversion have been used with good results. ${ }^{4-9}$

The Woven Endoluminal Bridge-Dual Layer (WEB-DL; Se-

Received March 3, 2014; accepted after revision April 21.

From the Department of Neuroradiology (C.P., D.H.), Centre Hospitalier Universitaire (CHU) Tours, Tours, France; Department of Neuroradiology (L.S., J.M.), Hôpital Beaujon, Assistance Publique-Hôpitaux de Paris, Clichy, France; Department of Neuroradiology (A.-C.J., C.C.), CHU Toulouse, Toulouse, France; Department of Neuroradiology (A.B., L.P.), CHU Reims, Reims, France; Department of Neuroradiology (J.-Y.G.), CHU Rennes, Rennes, France; Department of Neuroradiology (V.C.), CHU Montpellier, Montpellier, France; Department of Neuroradiology (H.D.), CHU Nantes, Nantes, France; Department of Neuroradiology (F.T.), CHU Lyon, Lyon France; Department of Neuroradiology (S.V.), CHU Poitiers, Poitiers, France; Department of Neuroradiology (X.B.), CHU Bordeaux, Bordeaux, France; and Department of Neuroradiology (P.C.), CHU Caen, Caen, France.

Please address correspondence to Laurent Pierot, MD, Service de Radiologie, Hôpital Maison-Blanche, 45 Rue Cognacq-Jay, 51092 Reims cedex, France; e-mail: Ipierot@gmail.com

Evidence-Based Medicine Level 2.

http://dx.doi.org/10.3174/ajnr.A4028 quent Medical, Aliso Viejo, California) is an intra-aneurysmal flow-disruption device, developed to modify the blood flow at the aneurysm neck. Preliminary clinical experience with the WEB has shown the clinical utility of this treatment in wide-neck bifurcation aneurysms. Several preliminary, small, retrospective series have shown good feasibility of the treatment, with a limited number of complications, low morbidity, and no mortality. ${ }^{10-13}$ However, because these series were small and conducted in highly specialized centers with a careful selection of cases, there was a need for a safety analysis in a larger series of patients treated in several neurointerventional units.

Regarding the efficacy of the method, these preliminary series have also shown good anatomic results but with a relatively high percentage of neck remnants $(33.3 \%-56.7 \%) .{ }^{10,12}$ Further analysis demonstrated that some of the neck remnants were, in fact, due to the opacification of the proximal recess of the WEB device. ${ }^{13}$ This proximal recess opacification has proved stable at midterm follow-up in a recent retrospective series that has also demonstrated good anatomic results and stability of aneurysm obliteration at midterm follow-up. ${ }^{13}$

The first patient treated with the WEB-DL device in France was in June 2011. Since this initial case, all further consecutive 
cases were prospectively included in a data base. The retrospective analysis of the patients treated between June 2011 and October 2013 is presented in this article.

\section{MATERIALS AND METHODS}

The study received institutional review board approval, and according to the study design, informed consent was waived.

\section{Study Design}

Patients treated consecutively with the WEB-DL between June 2011 and October 2013 in 11 French neurointerventional centers were prospectively included in the study.

The indication for treatment and the technique chosen (surgery or endovascular) were decided for both ruptured and unruptured aneurysms by a multidisciplinary team consisting of neurosurgeons, interventional neuroradiologists, and neuroanesthesiologists in each center. The selection of the aneurysms for treatment with a WEB device was made by the interventional neuroradiology team of each center according to the aneurysm characteristics (location, size, and neck size).

\section{WEB Device}

There are now several WEB devices available in Europe, including the WEB Dual Layer, the WEB Single Layer (WEB-SL), and the WEB-Single Layer Spherical. In the present series, all patients and all aneurysms were treated with the WEB-DL. All WEB devices received European Conformity Mark for unruptured and ruptured aneurysms.

The WEB-DL is a self-expanding, oblate, braided, nitinol mesh. The device is composed of inner and outer braids held together by proximal, middle, and distal radiopaque markers creating 2 compartments: 1 distal and 1 proximal. Blood flow into a WEB-embolized aneurysm initially encounters 2 layers comprising 216 or 288 wires with the largest interwire distance ranging from 106 to $181 \mu \mathrm{m}$, respectively, depending on the device size. The WEB implant is deployed-or retrieved before detachment-similar to deployment in endovascular coil systems, through microcatheters with an internal diameter of $\geq 0.027$ inches. The detachment system is electrothermal and instantaneous. ${ }^{5,7}$

\section{Data Collection}

Information regarding sex, age, aneurysm characteristics (location, rupture status, size, neck size), initial modified Rankin Scale score, endovascular procedure technique, and immediate outcome was registered as well as all peri- and postprocedural complications. All patients had a clinical examination or telephonic interview 1 month after the procedure with evaluation by the mRS score. Aneurysm occlusion was evaluated by using DSA, MRA, or CTA according to the protocol of each center.

\section{Data Analysis}

Population characteristics, feasibility of the treatment, peri- and postprocedural complications, morbidity (defined as mRS $>1$ ), and mortality at 1 month were analyzed. Last follow-up imaging (DSA or MRA) results were used to evaluate the quality of aneu- rysm occlusion by using the 3-grade Montreal scale (total occlusion, neck remnant, aneurysm remnant).

\section{RESULTS}

\section{Population}

Eighty-three patients ( 57 women and 26 men) with 85 aneurysms, $34-75$ years of age (mean, $56.0 \pm 8.8$ years), were included. Twentytwo and 24 of the patients in these series also participated in the Woven Endoluminal Bridge Clinical Assessment of intraSaccular aneurysmal Therapy (WEBCAST) study and the French Observatory study, respectively.

Seventy-five aneurysms were unruptured $(88.2 \%), 4$ were ruptured $(4.7 \%)$, and $6(7.1 \%)$ were recanalized.

Forty-eight aneurysms were located on the MCA (56.5\%), 18 on the basilar artery $(21.2 \%), 11$ on the anterior communicating artery (AcomA) (12.9\%), and 8 on the supraclinoid ICA (9.4\%). Aneurysm size varied from 4.6 to $13.8 \mathrm{~mm}$ (mean, $7.4 \pm 1.4 \mathrm{~mm}$ ). Size was $<5$ $\mathrm{mm}$ in 4 aneurysms (4.7\%), between 5 and $10 \mathrm{~mm}$ in 73 aneurysms $(85.9 \%)$, and $>10 \mathrm{~mm}$ in 8 aneurysms $(9.4 \%)$. Neck size was between 2.6 and $9.5 \mathrm{~mm}$ (mean, $5.6 \pm 1.5 \mathrm{~mm}$ ). Neck size was $<4 \mathrm{~mm}$ in 12 aneurysms (14.1\%) and $>4 \mathrm{~mm}$ in 73 aneurysms (85.9\%).

All procedures were performed with the patient under systemic heparinization. After femoral puncture, a bolus of intravenous weight-adjusted heparin ( $50 \mathrm{IU} / \mathrm{kg}$ ) was given, followed by a continuous IV administration of $30 \mathrm{IU} / \mathrm{kg} / \mathrm{h}$. Heparin administration was then adjusted with activated clotting time aiming for $2-3$ times. Fifteen of 83 patients $(18.1 \%)$ did not have any antiplatelet treatment during or after treatment, 44 (53.0\%) had 1 antiplatelet agent continued for 1 month after treatment, and 24 (28.9\%) received double antiplatelet treatment also continued after treatment. Of these 24 patients, 4 had adjunctive stent placement for the treatment of their aneurysm.

\section{Treatment Feasibility}

Technical success (deployment of the WEB in the target aneurysm) was achieved in 77 patients $(92.8 \%)$ with 79 aneurysms (92.9\%) (Figs 1 and 2). The remaining 6 patients (7.2\%) with 6 unruptured aneurysms were successfully treated with coiling alone ( 1 patient), balloon-assisted coiling ( 3 patients), and stentassisted coiling (2 patients), uneventfully (Fig 3). The reasons for deployment failure were the following: difficulty in navigating the WEB delivery microcatheter in tortuous anatomy (3 patients with AcomA aneurysms) and inadequate visualization of the device, leading to the inability to verify the patency of the bifurcation branches arising from the aneurysm neck (3 patients with $2 \mathrm{MCA}$ aneurysms and 1 basilar tip aneurysm). Most of these cases were the first ones in the centers.

\section{Additional Treatment}

Nine of 79 aneurysms successfully treated with the WEB (11.4\%) received additional endovascular treatment after the WEB deployment. All were unruptured aneurysms, and the additional treatment was standard coiling in 6 aneurysms, balloon-assisted coiling in 1 aneurysm, and stent-assisted coiling in 2 aneurysms. The reasons for additional treatment after the WEB deployment were the following: 1) persisting aneurysm filling of complexshaped aneurysms for which the operator decided to perform a 

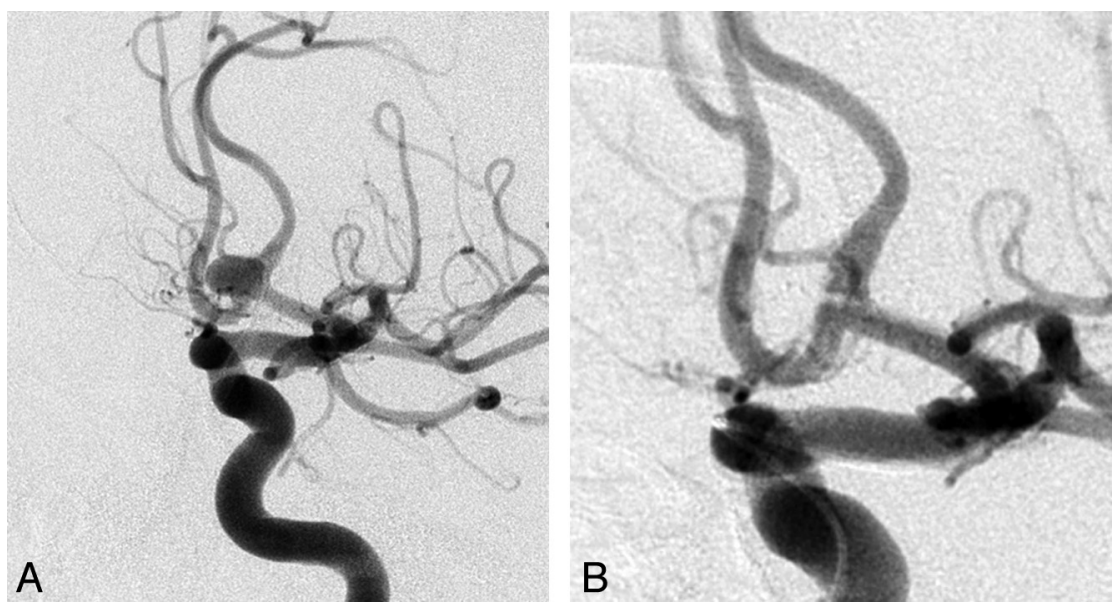

FIG 1. Anterior communicating artery unruptured aneurysm with a wide neck, before $(A)$ and immediately after (B) WEB deployment.
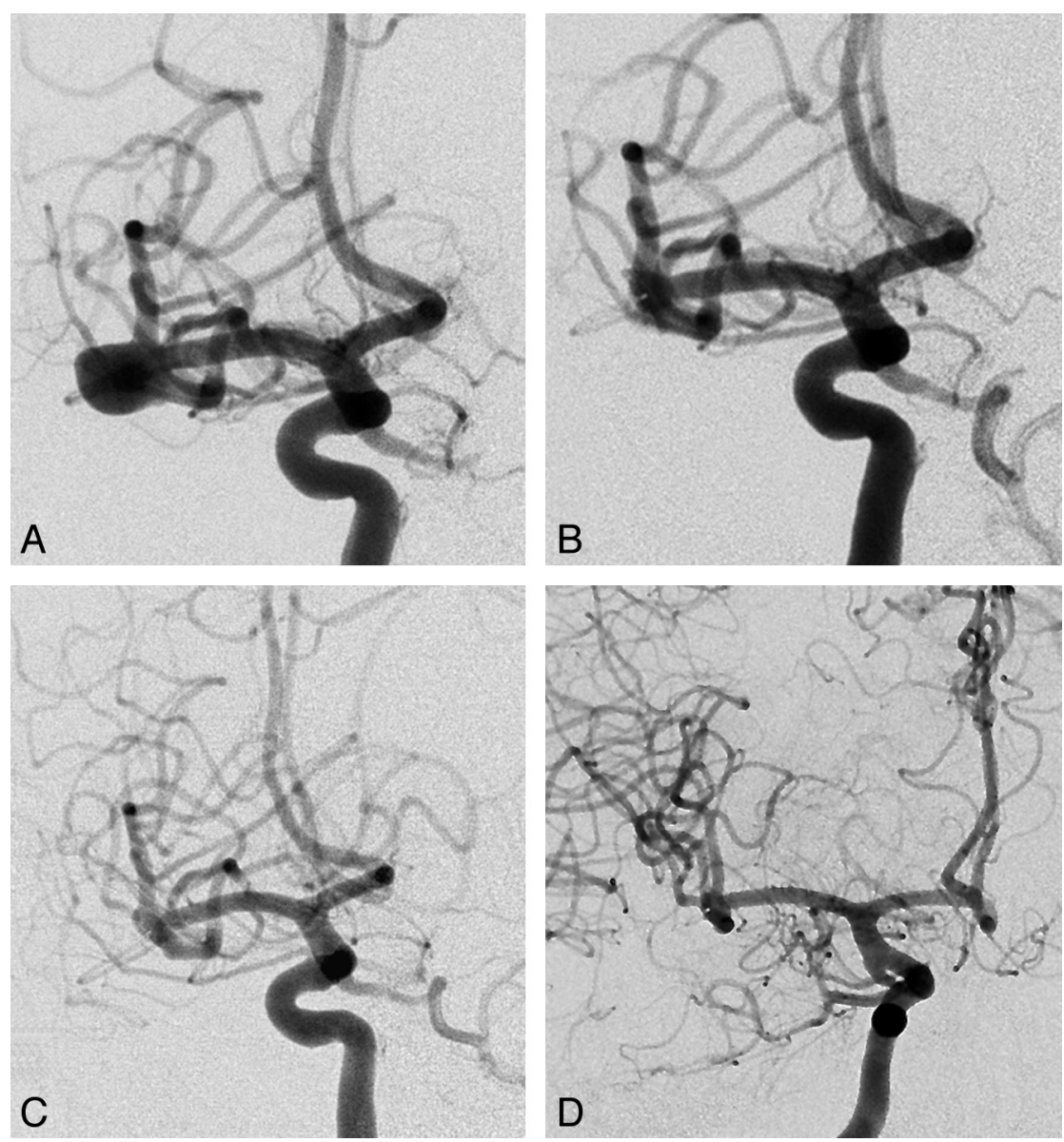

FIG 2. Middle cerebral bifurcation wide-neck unruptured aneurysm before $(A)$ and immediately after (B) WEB deployment. Eight-month follow-up DSA, working projection (C) and frontal projection (D).

device detachment was observed, without clinical worsening (1/77 patients, $1.3 \%)$. Intraoperative rupture occurred in $1 / 77$ patients $(1.3 \%)$. This patient presented with massive SAH (Fisher grade IV) and multiple aneurysms with 2 treated with the WEB. An intraoperative rupture occurred during the placement of the WEB in a ruptured AcomA aneurysm (Hunt and Hess scale 3 ), and a thromboembolic complication occurred during the treatment, at the same session, of an unruptured MCA aneurysm. Thromboembolic events occurred in 9/77 patients $(11.7 \%)$ during treatment (including the patient presenting with 2 complications). One patient was treated for a ruptured MCA aneurysm, and the remaining 8 patients were treated for unruptured or recanalized aneurysms (6 MCA aneurysms, 1 AcomA aneurysm, and 1 basilar artery aneurysm). Three patients (3.9\%) presented with a transient neurologic deficit, and 3 , with a permanent deficit $(3.9 \%)$. The remaining 3 patients $(3.9 \%)$ did not have any neurologic symptoms.

There were no postoperative complications such as a thromboembolic event, delayed rupture, or delayed intraparenchymal hematoma observed.

\section{One-Month Clinical Follow-Up}

From the 77 patients who were eventually treated with a WEB, 2 were lost to follow-up (2.6\%). The remaining 75 patients (77 aneurysms) underwent a clinical control 1 month after embolization.

Seventy-one of 75 patients $(94.7 \%)$ had mRS 0. Three patients (4.0\%) presented with mRS 1 . Two were treated for unruptured aneurysms and had intraoperative thromboembolic events (1 basilar tip and 1 AcomA), and the third was treated for recanalization of a previously ruptured MCA aneurysm and was already mRS 1 before retreatment with the WEB. One patient treated at the acute phase of subarachnoid hemorrhage (World Federation of Neurosurgi-

complete neck occlusion to ensure aneurysm occlusion or 2) programmed staged embolization in which the WEB was used to remodel a large complex-shaped aneurysm so that it would then be better suited for classic endovascular procedures.

\section{Complications}

Perioperative complications occurred in 10/77 patients (13.0\%) during the treatment of 11 aneurysms (Table). One inadvertent cal Societies III) had both intraoperative rupture (of an initially ruptured AcomA aneurysm) and a thromboembolic event (during the simultaneous treatment of an unruptured MCA aneurysm [see above]). This patient had mRS 3 at 1 month (1.3\%).

In total, a good outcome (mRS $0-1$ ) was observed in $96.1 \%$ of patients. Morbidity and mortality at 1 month were $1.3 \%$ and $0.0 \%$, respectively. Considering the 2 patients lost to follow-up as 
an unfavorable outcome, the total rate of unfavorable outcomes was $3.9 \%$ (3/77 patients).

\section{Short-Term Anatomic Results}

Of the 77 patients with 79 aneurysms that were eventually treated with a WEB, 63 patients (81.8\%) with 65 aneurysms $(82.3 \%)$ had an imaging control 3-24 months after treatment (mean, 5.3 \pm 2.9 months), 52 by DSA, 10 by MRA, and 1 by CTA (dual-energy CT). Limited artifacts were observed with MRA and CTA.

Of the 65 aneurysms, $37(56.9 \%)$ presented with complete occlusion at follow-up; 23 (35.4\%), with a neck remnant; and 5 $(7.7 \%)$, with an aneurysm remnant. Adequate aneurysm occlusion (total occlusion or neck remnant) was observed in 60/65 $(92.3 \%)$ of the aneurysms that had an imaging control.

For the 9 patients treated with a WEB who had an additional
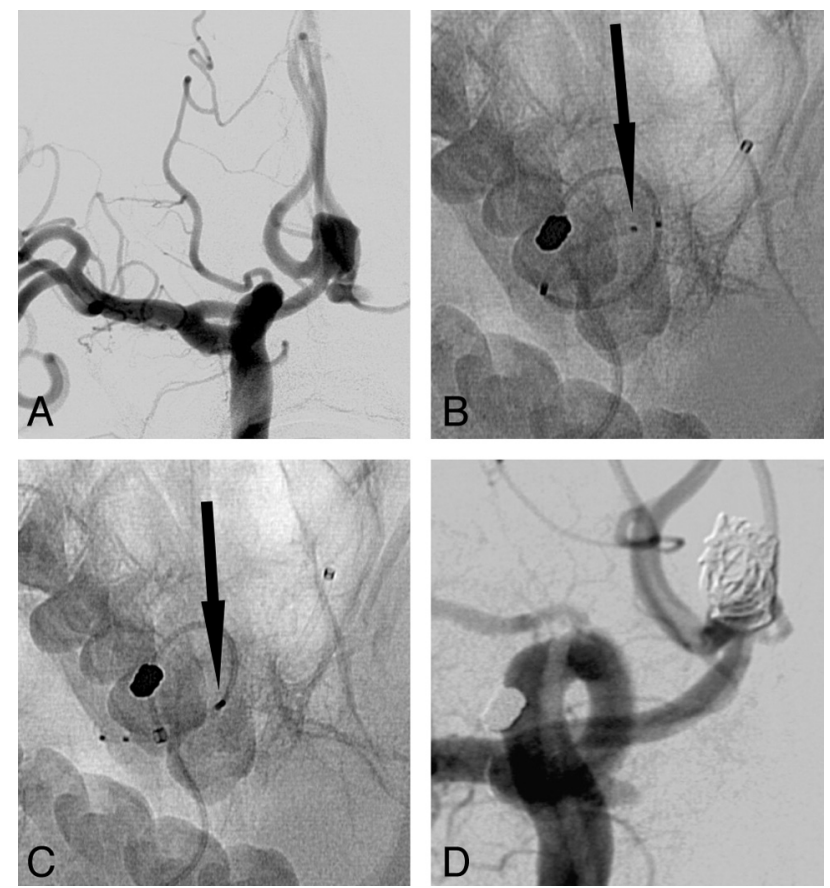

FIG 3. Failure to deploy the WEB due to the tortuous vessel anatomy. A, Unruptured AcomA aneurysm. B, WEB-DL (arrow on the second of 3 marker bands) could not be advanced through a tortuous turn by using only the delivery catheter. C, WEB-DL could not be advanced through the tortuous turn with intermediate catheter support of the delivery catheter (arrow shows the proximal marker of the WEB). D, Final result after balloon-assisted coiling of the aneurysm. treatment, the aneurysm occlusion rate at follow-up was complete occlusion in 3 , neck remnant in 4 , and aneurysm remnant in 1 patient (1 patient had not been followed up).

At the present time, none of the patients presenting with neck remnants or aneurysm remnants at follow-up have been retreated.

\section{DISCUSSION}

The present, large, multicenter series confirms the results of the preliminary, small, retrospective series dealing with WEB aneurysm treatment. ${ }^{10-12}$ The treatment is highly feasible (92.9\%) with a low complication rate $(11.7 \%)$, low permanent morbidity (1.3\%), and no mortality. At short-term follow-up, adequate occlusion (complete occlusion or neck remnant) was observed in 92.3\% of aneurysms.

Intrasaccular flow disruption is an innovative endovascular treatment that aims to create thrombosis of the aneurysmal sac by disrupting the blood flow in the aneurysm by covering its neck with an intrasaccular device. According to series presented in the literature, this approach applies mainly to complex wide-neck bifurcation aneurysms (MCA, basilar artery, AcomA, ICA). ${ }^{10-13}$ Most aneurysms in our series are unruptured $(88.2 \%)$, but treatment is also feasible for ruptured aneurysms (4.7\%). Because no antiplatelet medication is needed for aneurysm treatment with the $\mathrm{WEB}$, a rapid thrombosis of at least of the distal compartment and aneurysm dome is usually observed, which makes the device suitable for ruptured aneurysm treatment in the acute phase of a subarachnoid hemorrhage. The main reason for the low percentage of ruptured aneurysms treated in the present series is logistic organization, with no permanent material supply in most of the participating centers. Due to the small number of patients with ruptured aneurysms treated in this series, it is not possible to conduct a meaningful analysis of this subgroup. Retreatment of previously embolized, recanalized aneurysms is also feasible with the WEB (7.1\%).

WEB treatment failures were encountered in $6 / 83$ patients (7.1\%) due to navigation difficulties (3 patients) or inadequate visualization of the device ( 3 patients). The microcatheters used for the WEB deployment are relatively larger compared with those used for simple coiling; this difference makes it more difficult to navigate in tortuous anatomy, which mainly applies to AcomA aneurysms. After deployment, the WEB position is sometimes difficult to verify completely, due to poor visualization of the device, especially when it is superimposed on bony structures of the skull base. Improvement of its radiopacity will potentially im-

\begin{tabular}{|c|c|c|c|c|c|c|c|}
\hline Patient & Age (yr) & Sex & Aneurysm Location & Aneurysm Size (mm) & Status & Complication & Outcome (1-Month mRS) \\
\hline \multirow[t]{2}{*}{$1^{a}$} & 50 & $\mathrm{~F}$ & AcomA & 5.6 & Ruptured & IOR & 3 \\
\hline & & & MCA & 6.0 & Unruptured & TE & \\
\hline 2 & 66 & $\mathrm{~F}$ & MCA & 6.5 & $\operatorname{Rec}$ & $\mathrm{TE}$ & 0 \\
\hline 3 & 45 & $\mathrm{~F}$ & MCA & 7.2 & Unruptured & TE & 0 \\
\hline 4 & 69 & $\mathrm{~F}$ & $\mathrm{BA}$ & 7.0 & Unruptured & TE & 1 \\
\hline 5 & 66 & M & MCA & 9.3 & Unruptured & TE & 0 \\
\hline 6 & 46 & M & MCA & 8.5 & Unruptured & TE & 0 \\
\hline 7 & 63 & $\mathrm{~F}$ & MCA & 5.6 & Unruptured & TE & 0 \\
\hline 8 & 53 & $\mathrm{~F}$ & MCA & 9.5 & Ruptured & TE & 0 \\
\hline 9 & 56 & M & AcomA & 8.0 & Unruptured & TE & 1 \\
\hline 10 & 49 & $\mathrm{~F}$ & BA & 8.0 & Unruptured & ID & 0 \\
\hline
\end{tabular}

Note:-BA indicates basilar artery; Rec, recanalization; IOR, intraoperative rupture; ID, inadvertent detachment; TE, thromboembolic events

a Patient 1 had 2 aneurysms treated in the same session and 2 complications. 
prove the feasibility of the treatment. In fact, the failure rate is not higher compared with that observed with standard coiling if one takes into account the complexity of aneurysms treated with the WEB and the learning curve in each center (this series includes the first cases treated in each center). In the Gallas et al ${ }^{14}$ series, dealing with the treatment of 321 unruptured aneurysms with Guglielmi detachable coils (Stryker, Kalamazoo, Michigan), the failure rate was $6.0 \%$. In the Analysis of Treatment by Endovascular Approach of Nonruptured Aneurysms (ATENA) and Clinical and Anatomic Results in the Treatment of Ruptured Intracranial Aneurysms (CLARITY) studies, ${ }^{2,3}$ the failure rate was, respectively, $6.0 \%$ and $0.7 \%$, given that the percentage of wide-neck aneurysms was $30.9 \%$ in ATENA and $9.1 \%$ in CLARITY compared with $85.9 \%$ in the present series.

The rate of adverse events reported in this series (13.0\%) is similar to that observed in ATENA (13.4\%) or CLARITY $(17.0 \%){ }^{2,3}$ The rate of intraoperative rupture (1.3\%) was slightly lower compared with those in ATENA (2.6\%) and CLARITY (3.7\%). In addition, the rate of thromboembolic events $(11.7 \%)$ was very similar to those reported in ATENA (7.1\%) and CLARITY $(13.3 \%)$. In Naggara et al, ${ }^{15}$ a review of the endovascular treatment of unruptured aneurysms, thromboembolic events occurred at a rate of $7.6 \%$, leading to an unfavorable outcome in $4.8 \%$ of patients and death in $1.9 \%$. Treatment morbidity and mortality with the WEB $(1.3 \%$ and $0.0 \%)$ are consistent with those reported in ATENA (respectively, 1.7 and 1.4\%) and CLARITY (respectively, 3.7\% and 1.5\%). ${ }^{2,3}$

In our series, aneurysm occlusion was evaluated at short-term follow-up in a high percentage of aneurysms (82.3\%). Adequate aneurysm occlusion (total occlusion or neck remnant) was observed in a high percentage of aneurysms (92.3\%). The results reported in the CLARITY series are slightly worse, with an adequate occlusion rate of $81.2 \%$, but the results are, in fact, not really comparable because most aneurysms in the present series were unruptured (CLARITY was dealing exclusively with ruptured aneurysms) and the follow-up was shorter in the present series compared with CLARITY. ${ }^{16}$ However, the percentage of wide-neck aneurysms was clearly higher in the present series compared with CLARITY (respectively, 85.9\% and 9.1\%), and this is a well-known factor for aneurysm recanalization. ${ }^{17}$ Neck remnants observed in our series were relatively high (35.4\%). As outlined in a recent article, what is classified as a "neck remnant" after WEB treatment is not always a true neck remnant but is often an opacification of the proximal recess of the WEB device, which will be stable for a long time and has, in fact, been classified as complete occlusion. $^{13}$

Our series has several limitations. Patients were prospectively included, but data were retrospectively collected and analyzed. In addition, the clinical and anatomic results were evaluated by the neurointerventional teams that performed the procedures, without an independent core lab. All patients were treated with the WEB-DL device, and further studies are necessary to analyze the safety and efficacy of the WEB-Single Layer and WEB-Single Layer Spherical devices.

\section{CONCLUSIONS}

In this large multicenter series, the WEB device seems to be a promising tool for the treatment of complex wide-neck bifurca- tion aneurysms with equal safety and efficacy compared with other endovascular treatments. Of course, due to the small number of patients, subgroup analysis that could draw conclusions according to aneurysm size and location is not feasible and further studies are needed to establish the extent of indications for this kind of treatment.

Disclosures: Anne-Christine Januel—RELATED: Travel/Accommodations/Meeting Expenses Related to Activities Listed: Sequent Medical (World Live Neurovascular Conference 2013 in Istanbul) and proctoring for Sequent Medical. Laurent SpelleRELATED: proctoring for Sequent Medical, Travel/Accommodations/Meeting Expenses Related to Activities Listed: Sequent Medical, UNRELATED: Consultancy: Covidien/ev3 and Stryker. Jean-Yves Gauvrit-UNRELATED: Other: a core lab agreement for a European WEB series from Sequent. Vincent Costalat-UNRELATED: Consultancy: Covidien, Stryker, Codman, Balt, and Sequent, Payment for Lectures (including service on Speakers Bureaus): for the development of educational presentations from Covidien, Stryker, and MicroVention. He also discloses a limited research agreement with Sequent. Francis Turjman—RELATED: Fees for Participation in Review Activities (such as data monitoring boards, statistical analysis, endpoint committees, and the like): Sequent Medical, UNRELATED: Consultancy: Covidien, Balt, and Codman, Grants or Grants Pending: Covidien, Payment for Lectures (including service on Speakers Bureaus): Covidien and Codman, Payment for the Development of Educational Presentations: Covidien, Travel, Accommodations, or Meeting Expenses: Covidien and Codman. Xavier Barreau-RELATED: Consulting Fees or Honoraria: Sequent Medical, UNRELATED: Consultancy: MicroVention, Codman, and Covidien, Payment for Lectures (including service on Speakers Bureaus): Codman, Travel, Accommodations, or Meeting Expenses: Covidien and Codman. * Christophe Cognard-RELATED: Consulting Fees or Honoraria: Sequent Medical for proctoring, Support for Travel to Meetings for the Study or Other Purposes: Subsequent. UNRELATED: Consultancy: Stryker, MicroVention, Sequent, Codman, and Covidien. Denis Herbreteau-UNRELATED: Consultancy: Sequent and Covidien. Jacques Moret-UNRELATED: Consultancy: Covidien and MicroVention. Laurent Pierot-RELATED: Proctoring and Consultancy: Sequent Medical, Principal Investigator for WEBCAST and French Observatory, RELATED: Consulting Fees or Honoraria: Sequent Medical, UNRELATED: Consultancy: Covidien/ev3, MicroVention, and Penumbra. ${ }^{*}$ Money paid to the institution.

\section{REFERENCES}

1. Molyneux A, Kerr R, Stratton I, et al, for the International Subarachnoid Aneurysm Trial (ISAT) Colaborative Group. International Subarachnoid Aneurysm Trial (ISAT) of neurosurgical clipping versus endovascular coiling in 2143 patients with ruptured intracranial aneurysms: a randomised trial. Lancet 2002;360:1267-74

2. Cognard C, Pierot L, Anxionnat R, et al, for the Clarity Study group. Results of embolization used as the first treatment choice in a consecutive nonselected population of ruptured aneurysms: clinical results of the Clarity GDC study. Neurosurgery 2011;69:837-41

3. Pierot L, Spelle L, Vitry F, for the ATENA Investigators. Immediate clinical outcome of patients harbouring unruptured intracranial aneurysms treated by endovascular approach: results of the ATENA trial. Stroke 2008;39:2497-504

4. Pierot L, Cognard C, Spelle L, et al. Safety and efficacy of balloon remodeling technique during endovascular treatment of intracranial aneurysms: critical review of the literature. AJNR Am J Neuroradiol 2012;33:12-15

5. Pierot L, Spelle L, Leclerc C, et al. Endovascular treatment of unruptured intracranial aneurysms: comparison of safety of remodeling technique and standard treatment with coils. Radiology 2009;251:846-55

6. Pierot L, Cognard C, Anxionnat R, et al. for the CLARITY Investigators. Remodeling technique for endovascular treatment of ruptured intracranial aneurysms had a higher rate of adequate postoperative occlusion than did conventional coil embolization with comparable safety. Radiology 2011;258:546-53

7. Shapiro M, Becske T, Sahlein, et al. Stent-supported aneurysm coiling: a literature survey of treatment and follow-up. AJNR Am J Neuroradiol 2012;33:159-63

8. Pierot L. Flow diverter stents in the treatment of intracranial aneurysms: where are we? J Neuroradiol 2011;38:40-46 
9. Berge J, Biondi A, Machi P, et al. Flow-diverter Silk stent for the treatment of intracranial aneurysms: 1-year follow-up in a multicenter study. AJNR Am J Neuroradiol 2012;33:1150-55

10. Pierot L, Liebig T, Sychra V, et al. Intrasaccular flow disruption: a new endovascular approach for the treatment of intracranial aneurysms-results of a preliminary clinical evaluation in a multicenter series. AJNR Am J Neuroradiol 2012;33:1232-38

11. Lubicz B, Mine B, Collignon L, et al. WEB device for endovascular treatment of wide-necked bifurcation aneurysms. AJNR Am J Neuroradiol 2013;34:1209-14

12. Pierot L, Klisch J, Cognard C, et al. Endovascular WEB flow disruption in middle cerebral artery aneurysms: preliminary feasibility, clinical, and anatomical results in a multicenter study. Neurosurgery 2013;73:27-34, discussion 34-35

13. Lubicz B, Klisch J, Gauvrit JY, et al. WEB-DL endovascular treatment of wide-neck bifurcation aneurysms: short- and midterm results in a European study. AJNR Am J Neuroradiol 2014;35:432-38

14. Gallas S, Drouineau J, Gabrillargues J, et al. Feasibility, procedural morbidity and mortality, and long-term follow-up of endovascular treatment of 321 unruptured aneurysms. AJNR Am J Neuroradiol 2008;29:63-68

15. Naggara ON, White PM, Guilbert F, et al. Endovascular treatment of intracranial unruptured aneurysms: systematic review and metaanalysis of the literature on safety and efficacy. Radiology 2010;256:887-97

16. Pierot L, Cognard C, Ricolfi F, et al, for the CLARITY investigators. Mid-term anatomic results after endovascular treatment of ruptured intracranial aneurysms with Guglielmi detachable coils and Matrix coils: analysis of the CLARITY series. AJNR Am J Neuroradiol 2012;33:469-73

17. Pierot L, Cognard C, Anxionnat R, et al, for the CLARITY investigators. Endovascular treatment of ruptured intracranial aneurysms: factors affecting midterm quality anatomic results: analysis in a prospective, multicenter series of patients (CLARITY). AJNR Am J Neuroradiol 2012;33:1475-80 